\title{
Comparison of Methods for Determining the Physical Parameters of the Resonator of a Solid-State Wave Gyroscope
}

\author{
R. I. Mingazov ${ }^{1}$, F. I. Spiridonov, I. A. Vikhlyaev, K. V. Shishakov \\ Radio Engineering Department of the Kalashnikov Izhevsk State Technical University \\ Izhevsk, Russian Federation \\ E-mail: ramzsjkee@gmail.com ${ }^{1}$
}

Received: July 15, 2020

\begin{abstract}
The article deals with the problem of identifying the dynamic parameters of the resonator of a solid-state wave gyroscope, based on the signals measured when the sensor is operating in free-run mode. The search for the dynamic parameters of a solid-state wave gyroscope is one of the most important operations of the quality control of its production. The paper describes two methods for determining the physical parameters of a quartz resonator of a solid-state wave gyroscope. For each method, the mathematical substantiation of the relationship between the dynamic behavior of the resonator and its physical parameters is given. On the basis of each of the techniques, an algorithmic support for the extraction of the physical parameters of the resonator of a solid-state wave gyroscope is presented. The research of the accuracy of calculating the visual parameters by the described methods on experimental data of a resonator with known parameters has been carried out. The results obtained show the practical applicability of the described methods. An example of using the methods described in the work is the identification and control of the dynamic parameters of a quartz hemispherical resonator of a solid-state wave gyroscope at the technological stage of "balancing".
\end{abstract}

Keywords: solid-state wave gyroscopes, dynamic parameters, conjugate gradient method, q-factor, different q-factor, different frequency, rigidity axes, viscosity axis

\section{INTRODUCTION}

Production cycle of hemispherical resonator gyroscope (HRG) includes a lot of technological operations, such as, operations of balancing control, different frequency, different Qquality, calibration and others [1-3]. These operations control the most important parameters that affect the accuracy of the output signals of the HRG, are performed by measuring the dynamic characteristics of standing waves of a quartz resonator [4-9]. Since the latter characteristics turn out to be strongly related to the dynamic parameters of the TVG resonator, therefore, the research of the accuracy of the models for identifying the physical parameters of the resonator was chosen as the topic of this article.

(C) R. I. Mingazov, F. I. Spiridonov, I. A. Vikhlyaev, K. V. Shishakov, 2020 


\section{THE PARAMETRIC STRUCTURE OF THE MEASURED SigNALS}

The wave processes observed by the measuring device have the following internal structure [1-3]:

$$
\begin{aligned}
& C(t)=A(t) \cos \theta(t) \cos (2 \pi \omega t+\varphi)-B(t) \sin \theta(t) \sin (2 \pi \omega t+\varphi), \\
& S(t)=A(t) \sin \theta(t) \cos (2 \pi \omega t+\varphi)+B(t) \cos \theta(t) \sin (2 \pi \omega t+\varphi),
\end{aligned}
$$

where $A(t)$ - amplitude of the main vibrations, $B(t)$ - amplitude of the quadrature oscillations, $\theta(t)$ - angular orientation of the wave, $\omega(t)$ - average oscillation frequency, $\varphi$ - initial phase displacement.

In the general case, these functions depend not only on time $t$, but also on the physical parameters of the HRG resonator:

$$
\begin{aligned}
& A(t)=\tilde{A}\left(\eta, \Delta \eta, \vartheta_{\eta}, \Delta v, \vartheta_{v}, t\right), \\
& B(t)=\tilde{B}\left(\eta, \Delta \eta, \vartheta_{\eta}, \Delta v, \vartheta_{v}, t\right), \\
& \theta(t)=\tilde{\theta}\left(\eta, \Delta \eta, \vartheta_{\eta}, \Delta v, \vartheta_{v}, t\right) .
\end{aligned}
$$

where $\eta$-damping factor, $\Delta \eta$ - delta of the damping factor, $\theta_{\eta}$ - axis of maximum viscosity, $\Delta v-$ value of different frequency, and $\theta_{v}-$ axis of maximum stiffness.

The mathematical model of the rate of change of variables in the free-coast mode (without control action) is described by the equations [9-11]:

$$
\begin{gathered}
\dot{A}\left(\eta, \Delta \eta, \vartheta_{\eta}, \Delta v, \vartheta_{v}, t\right)=-\eta A(t)-2 \Delta \eta A(t) \cos 2\left(\theta(t)-\vartheta_{\eta}\right)-\Delta v B(t) \sin 2\left(\theta(t)-\vartheta_{v}\right), \\
\dot{B}\left(\eta, \Delta \eta, \vartheta_{\eta}, \Delta v, \vartheta_{v}, t\right)=-\eta B(t)+2 \Delta \eta B(t) \cos 2\left(\theta(t)-\vartheta_{\eta}\right)+\Delta v A(t) \sin 2\left(\theta(t)-\vartheta_{v}\right), \\
\dot{\theta}\left(\eta, \Delta \eta, \vartheta_{\eta}, \Delta v, \vartheta_{v}, t\right)=\frac{\left(-\Delta \eta\left(\sin 2 \theta(t) \cos 2 \vartheta_{\eta}+\cos 2 \theta(t) \sin 2 \vartheta_{\eta}\right)-g_{3}\right) A(t)^{2}}{A(t)^{2}-B(t)^{2}}+ \\
+\frac{\left(-\Delta \eta\left(\sin 2 \theta(t) \cos 2 \vartheta_{\eta}+\cos 2 \theta(t) \sin 2 \vartheta_{\eta}\right)+g_{3}\right) B(t)^{2}}{A(t)^{2}-B(t)^{2}}+ \\
+\frac{2 \Delta v\left(\cos 2 \theta(t) \cos 2 \vartheta_{v}+\sin 2 \theta(t) \sin 2 \vartheta_{v}\right) A(t) B(t)}{A(t)^{2}-B(t)^{2}}
\end{gathered}
$$

or

$$
\begin{gathered}
\dot{A}\left(\eta, \Delta \eta, \vartheta_{\eta}, \Delta v, \vartheta_{v}, t\right)=-\eta A(t)-2 \Delta \eta_{c} A(t) \cos 2 \theta-2 \Delta \eta_{s} A(t) \sin 2 \theta- \\
-\Delta v_{c} B(t) \sin 2 \theta+\Delta v_{s} B(t) \cos 2 \theta, \\
\dot{B}\left(\eta, \Delta \eta, \vartheta_{\eta}, \Delta v, \vartheta_{v}, t\right)=-\eta B(t)+2 \Delta \eta_{c} B(t) \cos 2 \theta+2 \Delta \eta_{s} B(t) \sin 2 \theta+ \\
+\Delta v_{c} A(t) \sin 2 \theta-\Delta v_{s} A(t) \cos 2 \theta, \\
\dot{\theta}\left(\eta, \Delta \eta, \vartheta_{\eta}, \Delta v, \vartheta_{v}, t\right)=\frac{\left(-\sin 2 \theta(t) \Delta \eta_{c}+\cos 2 \theta(t) \Delta \eta_{s}-g_{3}\right) A(t)^{2}}{A(t)^{2}-B(t)^{2}}+ \\
+\frac{\left(-\sin 2 \theta(t) \Delta \eta_{c}+\cos 2 \theta(t) \Delta \eta_{s}+g_{3}\right) B(t)^{2}}{A(t)^{2}-B(t)^{2}}+ \\
+\frac{2\left(\cos 2 \theta(t) \Delta v_{c}+\sin 2 \theta(t) \Delta v_{s}\right) A(t) B(t)}{A(t)^{2}-B(t)^{2}}
\end{gathered}
$$

where $\Delta \eta_{c}=\Delta \eta \cos 2 \theta_{\eta}, \Delta \eta_{s}=\Delta \eta \sin 2 \theta_{\eta}, \Delta v_{c}=\Delta v \cos 2 \theta_{v}, \Delta v_{s}=\Delta v \sin 2 \theta_{v}$. 


\section{CALCULATION OF THE PARAMETERS OF THE RESONATOR BY OBSERVING THE COAST}

Substituting all derivatives in (3) with first-order difference schemes on the sampling interval $T$ :

$$
\begin{aligned}
\frac{A^{i+1}-A^{i}}{T}= & -\eta A^{i+1 / 2}-2 \Delta \eta_{c} A^{i+1 / 2} \cos 2 \theta^{i+1 / 2}-2 \Delta \eta_{s} A^{i+1 / 2} \sin 2 \theta^{i+1 / 2}- \\
& -\Delta v_{c} B^{i+1 / 2} \sin 2 \theta^{i+1 / 2}+\Delta v_{s} B^{i+1 / 2} \cos 2 \theta^{i+1 / 2}, \\
\frac{B^{i+1}-B^{i}}{T}= & -\eta B^{i+1 / 2}+2 \Delta \eta_{c} B^{i+1 / 2} \cos 2 \theta^{i+1 / 2}+2 \Delta \eta_{s} B^{i+1 / 2} \sin 2 \theta^{i+1 / 2}+ \\
& +\Delta v_{c} A^{i+1 / 2} \sin 2 \theta^{i+1 / 2}-\Delta v_{s} A^{i+1 / 2} \cos 2 \theta^{i+1 / 2}, \\
\frac{\theta^{i+1}-\theta^{i}}{T}= & \frac{\left(-\sin \left(2 \theta^{i+1 / 2}\right) \Delta \eta_{c}+\cos \left(2 \theta^{i+1 / 2}\right) \Delta \eta_{s}-g_{3}\right) A^{i+1 / 2} \cdot A^{i+1 / 2}}{A^{i+1 / 2} A^{i+1 / 2}-B^{i+1 / 2} B^{i+1 / 2}} \\
+ & \frac{\left(-\sin \left(2 \theta^{i+1 / 2}\right) \Delta \eta_{c}+\cos \left(2 \theta^{i+1 / 2}\right) \Delta \eta_{s}+g_{3}\right) B^{i+1 / 2} \cdot B^{i+1 / 2}}{A^{i+1 / 2} A^{i+1 / 2}-B^{i+1 / 2} B^{i+1 / 2}} \\
+ & \frac{2\left(\cos \left(2 \theta^{i+1 / 2}\right) \Delta v_{c}+\sin \left(2 \theta^{i+1 / 2}\right) \Delta v_{s}\right) A^{i+1 / 2} B^{i+1 / 2}}{A^{i+1 / 2} A^{i+1 / 2}-B^{i+1 / 2} B^{i+1 / 2}} .
\end{aligned}
$$

where the left and right sides of (4) are taken from the observed quantities $\{A, B$, theta $\}$.

After the left side of the equation system are collected in the vector dimension $\mathbf{h}(N, 1)$, right in the matrix $\mathbf{M}(N, 5)$ and the unknown vector is denoted $\mathbf{r}=\left[\eta, \Delta \eta_{c}, \Delta \eta_{s}, \Delta v_{c}, \Delta v_{s}\right]$, the system (4) can be written in matrix form [9]:

$$
\mathbf{h}=\mathbf{M} \times \mathbf{r} .
$$

Since the system of equations (5) is redundant, its solution is possible through minimization of the residual. This leads to the matrix equation:

$$
\mathbf{M}^{\mathrm{T}} \times \mathbf{h}=\mathbf{M}^{\mathrm{T}} \times \mathbf{M} \times \mathbf{r} \Rightarrow \mathbf{r}=\left(\mathbf{M}^{\mathrm{T}} \times \mathbf{M}\right)^{-1} \times \mathbf{M}^{\mathrm{T}} \times \mathbf{h} .
$$

To find the parameters of the HRG in coasting mode remains the problem of finding the wave variables.

\section{Numerical CALCUlation of WAVE VARIABLES}

In equation (1) the basic information functions are $\mathrm{A}(t), B(t), \theta(t)$, which is found by minimizing the functional errors:

$$
F=\sum_{i}\left(\begin{array}{c}
{\left[-C_{i}+A_{i} \cos \theta_{i} \cos \left(\tau_{i}\right)-B_{i} \sin \theta_{i} \sin \left(\tau_{i}\right)\right]^{2}+} \\
+\left[-S_{i}+A_{i} \sin \theta_{i} \cos \left(\tau_{i}\right)+B_{i} \cos \theta_{i} \sin \left(\tau_{i}\right)\right]^{2}
\end{array}\right) \rightarrow 0,
$$

To numerically minimize it by the vector of parameters, the conjugate gradient method was chosen. 


\section{TRANSITION TO NEW VARIABLES $(p, q, r)$.}

The calculation of the variables $[A, B, \theta]$ can be simplified by introducing the following new variables [8]:

$$
\begin{gathered}
c c=\frac{2}{N} \sum_{i} C_{i} C_{i}=A^{2} \cos ^{2}(\theta)+B^{2} \sin ^{2}(\theta)=\frac{1}{2}\left(A^{2}+B^{2}\right)+\frac{1}{2}\left(A^{2}-B^{2}\right) \cos (2 \theta), \\
c s=\frac{2}{N} \sum_{i} C_{i} S_{i}=\left(A^{2}-B^{2}\right) \sin (\theta) \cos (\theta)=\frac{1}{2}\left(A^{2}-B^{2}\right) \sin (2 \theta), \\
s s=\frac{2}{N} \sum_{i} S_{i} S_{i}=A^{2} \sin ^{2}(\theta)+B^{2} \cos ^{2}(\theta)=\frac{1}{2}\left(A^{2}+B^{2}\right)-\frac{1}{2}\left(A^{2}-B^{2}\right) \cos (2 \theta),
\end{gathered}
$$

Next we proceed from basis $[A, B, \theta]$ to a new basis:

$$
\begin{gathered}
p=c c-s s=\left(A^{2}-B^{2}\right) \cos (2 \theta), \\
q=2 c s=\left(A^{2}-B^{2}\right) \sin (2 \theta), \\
r=c c+s s=A^{2}+B^{2} .
\end{gathered}
$$

As a result, equations (3) will take the form:

$$
\begin{gathered}
\dot{p}=2 \eta p+2 g_{3} q+2 \Delta \eta_{c} r-4 A B \Delta v_{s}, \\
\dot{q}=-2 g_{3} p+2 \eta q+2 \Delta \eta_{s} r+4 A B \Delta v_{c}, \\
\dot{r}=2 \Delta \eta_{c} p+2 \Delta \eta_{s} q+2 \eta r,
\end{gathered}
$$

where $A B=\operatorname{sign}(B) \cdot \operatorname{sqrt}\left(r^{2}-p^{2}-q^{2}\right)$, as well as $g_{3}$ the projection of rotation rate of the earth.

Further, the system of equations (10) performed substitution derivatives on timedifference scheme first order in analogy to (4). The resulting system of equations is solved by analogy with (5), (6). And the result of its solution will be a vector $\left[\eta, \Delta \eta_{c}, \Delta \eta_{s}, \Delta v_{c}, \Delta v_{s}\right]$.

At the last phase of computations, the values of physical parameters are calculated using its values using the following formulas:

$$
\begin{gathered}
\vartheta_{\eta}=\frac{1}{4} \arctan \left(\frac{\Delta \eta_{s}}{\Delta \eta_{c}}\right), \vartheta_{v}=\frac{1}{4} \arctan \left(\frac{\Delta v_{s}}{\Delta v_{c}}\right), \\
Q=\frac{\pi \omega}{\eta}, \Delta Q=\frac{\pi \omega}{\sqrt{\Delta \eta_{c}^{2}+\Delta \eta_{s}^{2}}}, \Delta v=\sqrt{\Delta v_{c}^{2}+\Delta v_{s}^{2}} .
\end{gathered}
$$

where $\theta_{\eta}$ - axis of maximum viscosity, $\theta_{v}$ - axis of maximum stiffness, $Q-\mathrm{Q}$-factor, $\Delta Q-$ varied Q-factor, $\Delta v$ - different frequency.

\section{COMPARISON OF CALCULATION RESUlts}

HRG dynamic parameters were calculated by two methods according to formula (11). The math package Scilab was used for calculations.

In the first method, first solved (7), then from equation (4) is constructed in the matrix equation (5) and at the end, a system of equations (6).

In the second method, first phase variables are calculated by formulas (8), (9), then system (5) is constructed and the system of equations (6) is solved. 
For an example of calculating the parameters of the HRG resonator, the data obtained experimentally at the stand for balancing are used. The initial data were obtained from the HRG resonator in the form of signals $(C, S)(1)$, the measurement time was $60 \mathrm{sec}$, the sampling frequency of the ADC was $33333 \mathrm{~Hz}$.

Table 1 shows the results of calculating the parameters of the resonator. The calculation of one value of a slowly varying variable was carried out for 1 period of oscillations.

Table 1. Result of HRG resonator calculation

\begin{tabular}{cccc}
\hline Parameters & Ideal value & $\begin{array}{c}\text { Through the identification } \\
\text { of } \boldsymbol{A}, \boldsymbol{B}, \boldsymbol{\theta} \\
\left(\mathbf{1}^{\text {st }} \mathbf{\text { method } )}\right.\end{array}$ & $\begin{array}{c}\text { By calculating } \boldsymbol{p}, \boldsymbol{q}, \boldsymbol{r} \\
\mathbf{2}^{\text {nd }} \mathbf{\text { method } )}\end{array}$ \\
\hline Q-factor & 4210350.328 & 4196531.783 & 4193124.846 \\
Varied Q-factor (\%) & 7 & 7.21 & 2.96 \\
Axis of maximum viscosity, Degrees & 88.9 & 89.0547 & 86.654 \\
Different frequency, Hz & 0.0003 & 0.0002734 & 0.0005286 \\
Axis of maximum stiffness, Degrees & 61.4 & 60.9435 & 59.9534 \\
\hline
\end{tabular}

\section{CONCLUSION}

In this paper, mathematical models for determining the parameters of the resonator of a solid-state wave gyroscope are considered. Two computational methods for revealing the resonator parameters are analyzed. Each method has its own pros and cons. For example, the method based on the numerical minimization of the error functional by the least squares method has a higher accuracy than the method for calculating the values of $p, q, r$. Moreover, the second method has a lower computational complexity in comparison with the method of minimizing the error functional. It is also worth noting that the calculation of the parameters $p, q, r$ should be performed over the full period of resonator oscillations.

These algorithms for identifying the parameters of the resonator of a solid-state wave gyroscope can be widely used in the production of gyroscopic devices and devices based on it. For example, in such technological operations as: balancing, tuning and control.

\section{REFERENCES}

1. Matveev, V. A., Lipatnikov, V. I., \& Alehin, A. V. (1997). Proektirovanie volnovogo tverdotelnogo giroskopa [Designing of hemispherical resonator gyroscope]. Moscow, Russia : MGTU im. N. E. Baumana. (in Russian).

2. Lunin, B. S., Matveev, V. A., \& Basarab, M. A. (2014). Volnovoj tverdotel'nyj giroskop. Teorija i tehnologija [Hemispherical resonator gyro. Theory and technology]. Moscow, Russia : Radiotehnika, 176 pp. (in Russian).

3. Shishakov, K. V. (2018). Tverdotel'nye volnovye giroskopy: volnovye processy, upravlenie, sistemnaja integracija [Solid-state wave gyroscopes: wave processes, control, system integration]. Izhevsk, Russia : Publ. House of Izhevsk State Technical University. (in Russian).

4. Zhbanov, Yu. K., \& Kalenova, N. V. (2001). Surface unbalance of a hemispherical resonator gyro. Mechanics of Solids, 36(3), 7-12. 

the resonator of a solid-state wave gyroscope"

5. Maslov, A. A., Maslov, D. A., \& Merkurev, I. V. (2014). Identifikatsiya parametrov volnovogo tverdotel'nogo giroskopa s uchetom nelineynosti kolebaniy rezonatora [Parameter identification of hemispherical resonator gyro woth nonlinearity of the resonator]. Pribory i sistemy. Upravlenie, kontrol', diagnostika [Instruments and Systems. Monitoring, Control, and Diagnostics], (5), 18-23. (in Russian).

6. Levshonkov, N. V. (2013). Metody vesovoj balansirovki rotora sverhlegkogo vertoleta s soosnymi vintami [Methods of mass balancing an ultralight helicopter rotor with coaxial screws]. Vestnik Kazanskogo gosudarstvennogo technichecskogo universiteta im. A.N. Tupoleva [Bulletin of Tupolev KSTU], (2-1), 5-7. (in Russian).

7. Krivov, A. V., \& Abramov, I. V. (2016). Sovremennoe sostoyanie problem balansirovki rezonatorov tverdotelnogo volnovogo giroskopa [Current state of the problem of balancing resonators of a hemispherical resonator gyroscope]. In Molodye uchenye - uskoreniyu nauchno-technicheskogo progressa v XXI veke: 20-21 Apr., 2016 (pp. 195-200). Izhevsk, Russia : INNOVA. (in Russian).

8. Zhuravlev, V. F. (2016). Dvumernyy ostsillyator Van der Polya c vneshnim upravleniem [Van der Pol's controlled 2D oscillator]. Nelineynaya dinamika [Russian Journal of Nonlinear Dynamics], 12(2), 211-222. (in Russian). doi: 10.20537/nd1602004.

9. Krivov, A. V., Melnikov, R. V., Spiridonov, F. I., \& Trutnev, G. A. (2019). Opredelenie parametrov rezonatora tverdotel'nogo volnovogo giroskopa i modelirovanie po eksperimental'nym dannym [Determination of parameters of HRG resonator and experimental data modeling]. Vestnik Kazanskogo gosudarstvennogo technichecskogo universiteta im. A.N. Tupoleva [Bulletin of Tupolev KSTU], 75(2), 127-133. (in Russian).

10. Klimov, D. M., Zhuravlev, V. F., \& Zhbanov, Y. K. (2017). Kvartsevyi polusfericheskii resonator (Volnovoi tverdotel'nyi giroskop) [Quartz hemispherical resonator (Hemispherical resonator gyroscope)]. Moscow, Russia : Kim L. A. (in Russian).

11. Trutnev, G. A. (2015). The model of hemispherical resonator gyroscope in terms of slow variables [Model' tverdotel'nogo volnovogo giroskopa v medlennykh peremennykh]. Vestnik Udmurtskogo Universiteta. Matematika. Mekhanika. Komp'yuternye Nauki [Bulletin of Udmurt University. Mathematics, Mechanics, Computer Science], 25(3), 421-429. (in Russian). doi: 10.20537/vm150312. 